\title{
Development and validation of a new HPLC method with fluorescence detection for determination of Rasagiline Mesylate and its application to pharmaceutical dosage form
}

\author{
Mostafa M. H. Khali1 ${ }^{1 *}$, Hassan M. Hassan ${ }^{1}$ and Ahmed H. Elshafeey ${ }^{2}$ \\ ${ }^{1}$ Department of Chemistry, Faculty of Science, Ain Shams University, Cairo, 11566, Egypt, \\ ${ }^{2}$ Department of pharmaceutics and industrial Pharmacy, College of Pharmacy, Cairo University, Egypt.
}

\section{ARTICLE INFO}

Article history:

Received 12 March 2017

Accepted 12 April 2017

Keywords:

HPLC;

Validation;

Fluorescence

Rasagiline.

\begin{abstract}
A B S T R A C T
A reverse phase high performance liquid chromatographic method was developed and validated for the determination of Rasagiline Mesylate in the dosage form. Chromatographic separation was carried out on an RP-18 column using a mobile phase consisting of (acetonitrile: $0.02 \mathrm{M}$ ammonium acetate $(60: 40 \mathrm{v} / \mathrm{v})$. The flow rate was $1.0 \mathrm{ml} / \mathrm{min}$. Fluorescence detector was employed with excitation at $210 \mathrm{~nm}$ and emission at $288 \mathrm{~nm}$. The calibration curve was linear over the range $(0.5-3.00) \mu \mathrm{g} / \mathrm{ml}$ with a correlation coefficient of 0.998 . The simplicity and rapidity of the developed method made it very suitable for routine analysis of Rasagiline Mesylate in the tablet dosage form.
\end{abstract}

\section{Introduction}

Parkinson disease is recognized as one of the most common neurologic disorders, affecting about $1 \%$ of individuals older than 60 years ${ }^{[1]}$. The most important and debilitating symptoms of Parkinson's disease are those resulting from dopamine (DA) depletion in the nigrostriatal pathway ${ }^{[2]}$. The neurochemical basis of Parkinson disease involves loss of Dopamine level resulting from oxidation with monoamine oxidase $B$ which exists in corpus striatum of the brain. Rasagiline (N-propargyl-1-(R)-Aminoindan) is a novel, highly potent irreversible monoamine oxidase (MAO)-B inhibitor, anti-Parkinsonian drugs ${ }^{[3.4]}$. Rasagiline inhibits monoamine oxidase activity resulting in increasing the level of Dopamine in the brain ${ }^{[5]}$.

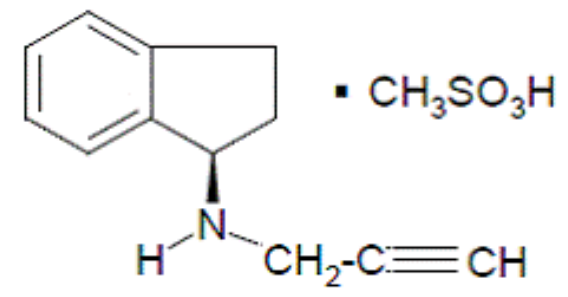

Fig. 1: Chemical structure of Rasagiline Mesylate ${ }^{[6]}$

There are some reported methods in the literature for quantification of Rasagiline Mesylate. For exampleSpectrophotometric methods ${ }^{[7,8]}$ to asses Rasagiline in

* Corresponding author.

E-mail address: Khali162@yahoo.com bulk with ranges $25-300 \mu \mathrm{g} / \mathrm{ml}$ and $39-273 \mu \mathrm{g} / \mathrm{mL}$, respectively. Also High performance liquid chromatography methods to determine Rasagiline in pharmaceutical dosage forms were reported ${ }^{[8,9]}$ with ranges $39-117 \mu \mathrm{g} / \mathrm{mL}, 0.5-20 \mu \mathrm{g} / \mathrm{mL}$. Moreover highperformance liquid chromatography with ultraviolet detection was developed for estimation of processrelated impurities and forced degradation products of Rasagiline Mesylate in pharmaceutical formulation ${ }^{[10]}$. In addition, an HPLC method for determination of Rasagiline Mesylate in plasma was reported [11]. Stability-Indicating HPTLC method was used for analysis of Rasagiline Mesylate in the bulk drug and tablet dosage form [12], LC-MS/MS methods for determination Rasagiline in plasma were also reported $[13,14]$

The aim of this study was to develop a new fluorescence detection method with high-performance liquid chromatography to determine Rasagiline in tablet dosage form with high sensitivity and its application in dissolution study for comparison between test and reference listed drug in vitro.

\section{Materials and methods}

\section{Instrumentation}

A High-Performance Liquid Chromatography (HPLC) was employed in this study consisted of a solvent delivery system (SHIMADZU LC-20AT, Japan) isocratic pump, Shimadzu Autosampler (Model SIL20A, Japan), a Spectrofluorometric detector (SHIMADZU Detector model RF-10Axl, Japan) 
equipped with a Xenon lamp and an automatically controlled, 200-650 (nm), a 12 $\mu$ l square quartz flow cell, Dissolution tester (Hanson vision ELITE 8, USA), Spectrophotometer (Shimadzu UV-1650pc UV-Vis Spectrophotometer, Japan) and Balance ( Shimadzu AUY 220, Japan).

\section{Reagents and chemicals}

Rasagiline mesylate reference standard was from Lupin Limited (Mumbai, India). Parkintreat $1 \mathrm{mg}$ Tablets from Inspire Pharmaceutical Company (Cairo, Egypt). Azilect ${ }^{\circledR}$ $1 \mathrm{mg}$ Tablets from Teva Pharmaceuticals (USA), HPLC grade water and hydrochloric acid are from Scharlau (Barcelona, Spain), Methanol and acetonitrile HPLC grade from Fischer scientific (Loughborough, United Kingdom), ammonium acetate from El Nasr pharmaceutical chemicals company (Qaliubiya, Egypt)

Selection of excitation and emission wavelengths of the method

Standard solution of $2 \mu \mathrm{g} / \mathrm{ml}$ Rasagiline was scanned between $200 \mathrm{~nm}$ to $400 \mathrm{~nm}$ with UV spectrophotometer. The maximum absorbance was found at $210 \mathrm{~nm}$. The same procedures were repeated using Fluorescence spectrophotometer scanner and the maximum emission wavelength was found to be $288 \mathrm{~nm}$.

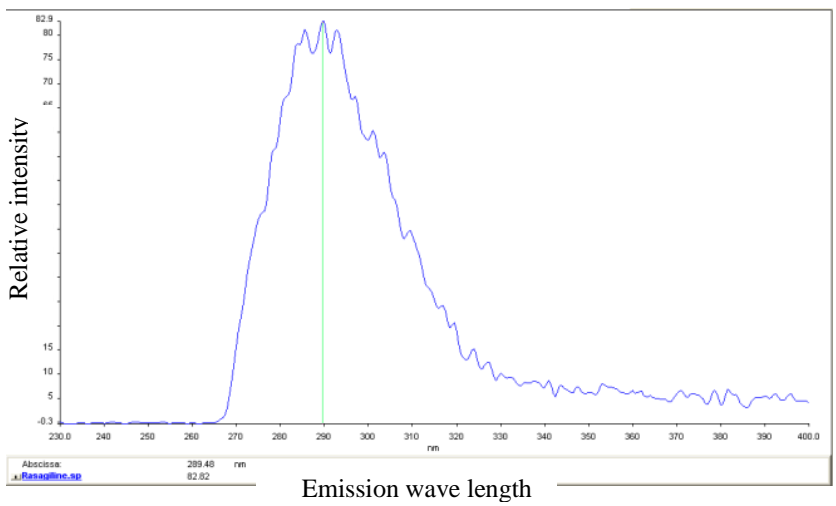

Fig. 2: Emission spectra of Rasagiline Mesylate

\section{Chromatographic conditions}

Isocratic elution of the mobile phase $0.02 \mathrm{M}$ Ammonium Acetate in water: Acetonitrile $(40: 60 \mathrm{v} / \mathrm{v})$ with the flow rate of $1 \mathrm{ml} / \mathrm{min}$. The contents of the mobile phase were filtered and degassed by sonication before use. Separation was performed on (Discovery $\mathrm{C} 18$ (Supleco) $(150 \times 4.6) \mathrm{mm}, 5 \mu \mathrm{m}$ particle size) as a column. The analysis was performed using the Shimadzu SpectroFluorometric detector to determine the peak area. The total run time was set at $6 \mathrm{~min}$. The injection volume was $100 \mu \mathrm{L}$. The wavelength used was at $210 \mathrm{~nm}$ Excitation, and $288 \mathrm{~nm}$ Emission. The developed method was validated in terms of accuracy, linearity, specificity, intra-day and inter-day precision and robustness for the assay of Rasagiline as per FDA guidelines.

\section{Standards and sample solutions preparation}

A stock solution of $400 \mu \mathrm{g} / \mathrm{ml}$ Rasagiline was prepared in methanol/water mixture $1: 1$, then $1.00 \mathrm{ml}$ of this solution was completed to $10 \mathrm{ml}$ with methanol/water mixture 1:1 to give a final concentration of $40 \mu \mathrm{g} / \mathrm{ml}$. Assay of rasagiline mesylate from its tablet dosage form

Twenty tablets (Parkintreat $1 \mathrm{mg}$ Tablets Inspire Pharmaceutical Company, Egypt) were weighed and finely powdered. A precisely weighed portion of the powder equivalent to $1 \mathrm{mg}$ of Rasagiline was extracted with methanol by the aid of sonication for five minutes. The extract was transferred to a $50 \mathrm{ml}$ volumetric flask and made up to the mark with the Methanol. The solution was filtered through a $0.45 \mu \mathrm{m}$ membrane filter. The tablet extract was appropriately diluted with mobile phase to obtain a concentration of $2 \mu \mathrm{g} / \mathrm{mL}$.

\section{Validation of the developed method}

The developed method was validated in terms of accuracy, linearity, specificity, intra-day and inter-day precision and robustness for the assay of Rasagiline as per FDA guidelines ${ }^{[15]}$.

\section{Specificity}

The specificity of the method was investigated by analyzing the drug product comparing with Rasagiline standard solution using the same chromatographic conditions defined for the method. It was found that there is no interference due to excipients in the tablet formulation.

\section{Linearity and range}

Linearity with range of $(0.5$ to 3.00$) \mu \mathrm{g} / \mathrm{ml}$ was prepared by taking the volumes of $(125,250,375$, $500,625,750) \mu \mathrm{l}$ from $40 \mu \mathrm{g} / \mathrm{ml}$ into $10 \mathrm{ml}$ flasks and complete with $0.1 \mathrm{~N}$ hydrochloric acid to get the following concentrations $(0.5,1.00,1.50,2.00,2.50$, $3.00) \mu \mathrm{g} / \mathrm{ml}$.

The linearity of Rasagiline was determined by plotting peak area versus concentrations.

\section{Accuracy and Precision}

The accuracy of the method was established by analyzing three different concentrations of Rasagiline $(0.50,1.00,2.50 \mu \mathrm{g} / \mathrm{mL})$. The precision of the method was established by injecting six replicate standard samples for the concentration $(2 \mu \mathrm{g} / \mathrm{mL})$ and the intermediate precision was determined by analyzing standard samples on two different days. Accuracy was expressed by evaluating the amount determined from the quality control standards and comparing to the respective nominal value expressed as percent recovery. Precision was expressed as the relative standard deviation of the analyte response.

\section{Robustness}

To determine the robustness of the method, experimental conditions such as $\mathrm{pH}$ of mobile phase and flow rate were slightly altered. The effect of small changes in chromatographic conditions was studied to verify the robustness of the method.

\section{Dissolution Test}

The dissolution tester consisted of a water bath maintained at $37^{\circ} \mathrm{C}$, eight vessels containing $500 \mathrm{ml}$ of $0.1 \mathrm{~N}$ hydrochloric acid solution as the dissolution medium which simulate the stomach. The apparatus used for stirring the drug and the medium of dissolution is 
called paddle or USP apparatus 2 that was set at $50 \mathrm{rpm}$ (rotation per minute) ${ }^{[16]}$.

Twelve tablets of each test and reference were tested after collection of $1 \mathrm{~mL}$ of each vessel at 10, 15, 30 and $45 \mathrm{~min}$ and a fresh dissolution medium of $1 \mathrm{~mL}$ was added after each collection of samples to keep the volume of dissolution constant. Samples were transferred from the vessels into vials after being filtered through a nylon filter $(0.45 \mu \mathrm{m})$ to be injected HPLC.

\section{Results and discussion}

\section{Chromatography optimization}

Different chromatographic conditions were optimized. The Fluorescence detector was set at $210 \mathrm{~nm}$ excitation and 288 for emission, different organic modifiers with different ratios, and different strengths of the buffer were tried also, different $\mathrm{pH}$ values for mobile phase, different types of stationary phases were tried to achieve the best separation within a short analysis time with the highest sensitivity.

\section{Validation}

\section{Specificity}

Specificity of the method was proved by the absence of interfering peaks from excipients present in formulations. Chromatograms obtained from tablets were almost identical to those obtained from the standard solutions.

\section{Linearity and range}

The linearity of the method was established over the analytical range of $0.50-3.00 \mu \mathrm{g} / \mathrm{ml}$ (Fig. 4). Good correlation between analyte peak area and concentration of the drug was obtained with correlation coefficient $(\mathrm{r} 2)=0.998$

\section{Accuracy and Precision}

Recovery experiments were employed to determine the accuracy of the proposed analytical method. Three different concentrations were prepared in triplicate $(25,75$ and $125 \%)$ of $2 \mu \mathrm{g} / \mathrm{ml}$ to be analyzed. The same three concentrations were compared to the standard solution. The values of recovery for injected samples showed high recovery values (100.39, 99.47 and $99.85 \%$, respectively). The recovery percentage results of the method are given in Table 1.

The results of the precision study are given in Table 2. The repeatability (within-day precision) expressed as RSD was $0.506 \%$. The intermediate precision (day-to-day) precision was up to $0.902 \%$

\section{Robustness}

The robustness of the method was studied by small changes in the method such as altering the mobile phase $\mathrm{pH}$, flow rate; sample solution of $2 \mu \mathrm{g} / \mathrm{ml}$ was injected in triplicate and the peak area RSD and were evaluated. It was observed that there were no changes in the chromatograms. The results are given in Table 3.

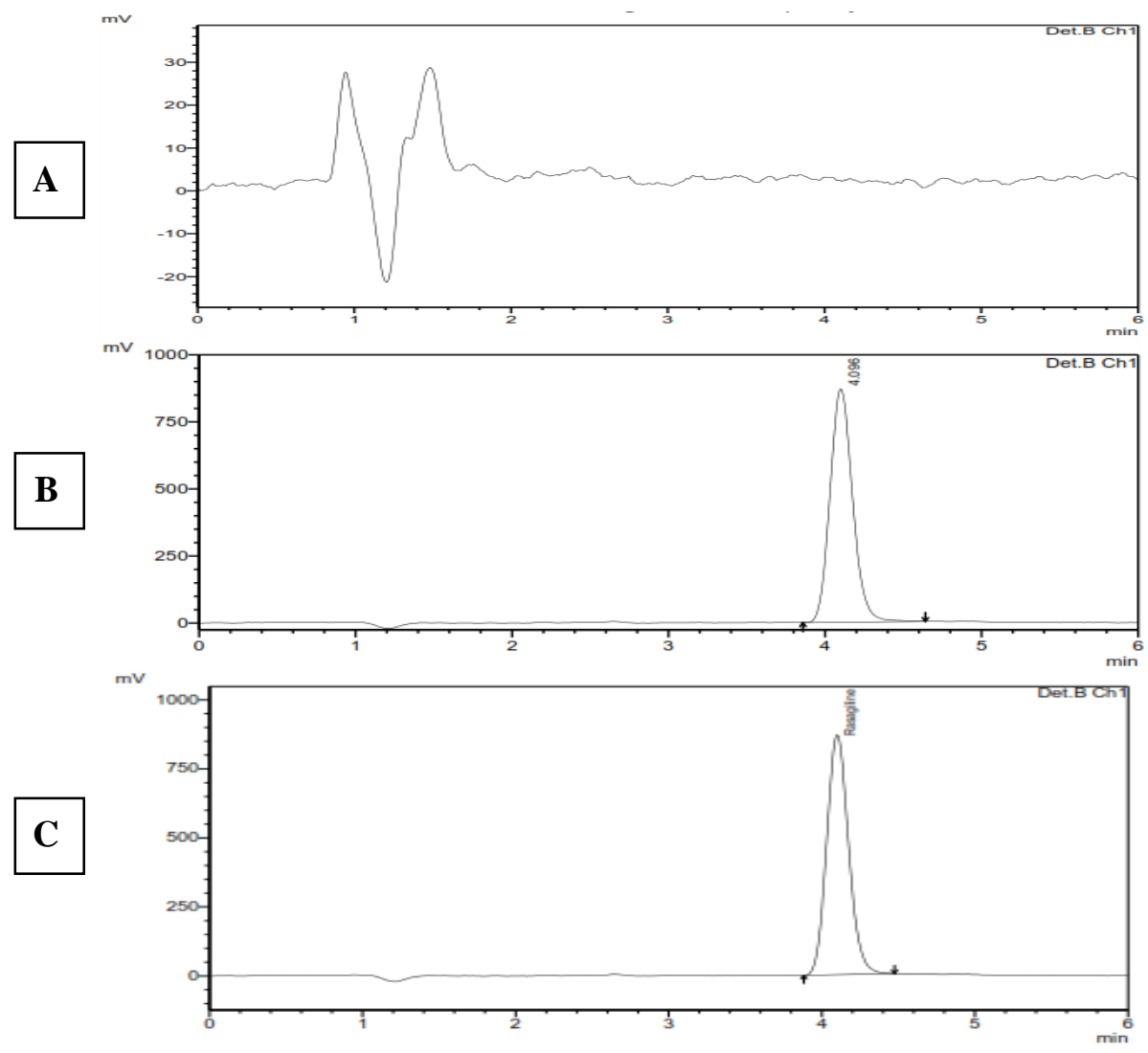

Fig. 3: Representative fluorescence chromatograms of Rasagiline Mesylate (A) chromatogram of blank, (B) chromatogram of $(2 \mu \mathrm{g} / \mathrm{ml})$ Rasagiline Mesylate in mobile phase. (C) Chromatogram of $(2 \mu \mathrm{g} / \mathrm{ml})$ Rasagiline Mesylate in tablet extract. 


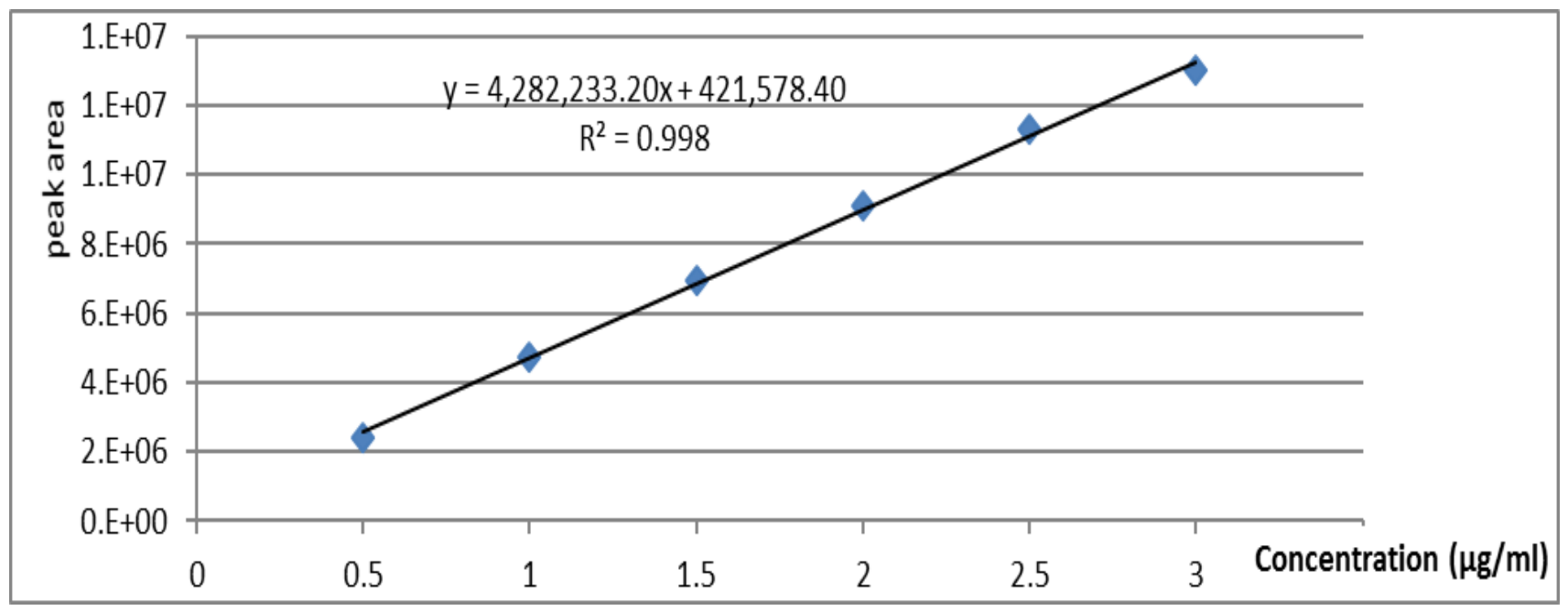

Fig. 4: Linearity range of Rasagiline Mesylate from $(0.5-3.00 \mu \mathrm{g} / \mathrm{ml})$.

Table (1): Results of the Recovery Tests for Rasagiline Mesylate

\begin{tabular}{|c|c|c|c|c|c|c|}
\hline $\begin{array}{l}\text { Sample } \\
\text { number }\end{array}$ & $\begin{array}{c}\text { Concentration } \\
\text { in } \mu \mathrm{g} / \mathrm{ml}\end{array}$ & $\begin{array}{l}\text { Standard } \\
\text { response }\end{array}$ & Response & \% Recovery & $\begin{array}{c}\text { Recovery } \\
\text { mean }\end{array}$ & $\begin{array}{l}\text { Recovery } \\
\text { RSD\% }\end{array}$ \\
\hline \multirow{3}{*}{1} & \multirow{3}{*}{0.5} & \multirow{3}{*}{2409844} & 2451746 & 101.74 & \multirow{3}{*}{100.39} & \multirow{3}{*}{1.20} \\
\hline & & & 2409727 & 100.00 & & \\
\hline & & & 2395907 & 99.42 & & \\
\hline \multirow{3}{*}{2} & \multirow{3}{*}{1.5} & \multirow{3}{*}{6939270} & 6892583 & 99.33 & \multirow{3}{*}{99.47} & \multirow{3}{*}{0.13} \\
\hline & & & 6907477 & 99.54 & & \\
\hline & & & 6908019 & 99.55 & & \\
\hline \multirow{3}{*}{3} & \multirow{3}{*}{2.5} & \multirow{3}{*}{11339689} & 11241382 & 99.13 & \multirow{3}{*}{99.85} & \multirow{3}{*}{0.62} \\
\hline & & & 11362734 & 100.20 & & \\
\hline & & & 11362869 & 100.20 & & \\
\hline
\end{tabular}

Table (2): Intraday and interday precision of the method

\begin{tabular}{|c|c|c|c|}
\hline Injection number & Concentration & $\begin{array}{l}\text { Intraday } \\
\text { precision }\end{array}$ & $\begin{array}{l}\text { Interday } \\
\text { precision }\end{array}$ \\
\hline 1 & \multirow{6}{*}{$2 \mu \mathrm{g} / \mathrm{ml}$} & 9054573 & 9959799 \\
\hline 2 & & 9073282 & 9733129 \\
\hline 3 & & 9055407 & 9944919 \\
\hline 4 & & 9007869 & 9976117 \\
\hline 5 & & 9064666 & 9874430 \\
\hline 6 & & 9149002 & 9898342 \\
\hline \multicolumn{2}{|l|}{ Mean } & 9067467 & 9897789 \\
\hline \multicolumn{2}{|l|}{ SD } & 45941.78 & 89286.75 \\
\hline \multicolumn{2}{|l|}{ RSD \% } & 0.51 & 0.90 \\
\hline
\end{tabular}


Table (3): Robustness of the method.

\begin{tabular}{|c|c|c|c|c|}
\hline Parameter & Variance & Concentration & Mean peak area & RSD n=3 \\
\hline \multirow{2}{*}{ Flow rate } & $1 \mathrm{ml} / \mathrm{min}$ & 9787430 & 0.40 \\
\cline { 2 - 3 } & $1.1 \mathrm{ml} / \mathrm{min}$ & $2 \mu \mathrm{g} / \mathrm{ml}$ & 10054888 & 0.85 \\
\cline { 2 - 3 } \multirow{2}{*}{ pH of mobile phase } & $\mathrm{pH}=7.25$ & & 9822276 & 0.89 \\
\cline { 2 - 2 } & $\mathrm{pH}=7.50$ & & 10360914 & 1.02 \\
\hline
\end{tabular}

\section{Dissolution test}

The method was applied for the analysis of Rasagiline Mesylate in comparison of Parkintreat $1 \mathrm{mg}$ Tablets as the generic Product against Azilect ${ }^{\circledR} 1 \mathrm{mg}$ Tablets As the Reference product.

\section{Calculations:}

$\mathrm{y}=5080997.8286 \mathrm{x}-29970.2$

$\mathrm{Y}=$ Peak Area

$\mathrm{X}=$ concentration $\mu \mathrm{g} / \mathrm{ml}$

$\%$ Dissolution $=\frac{\text { concentration }(\mu \mathrm{g} / \mathrm{ml}) * 500 * 100}{1 * 1000}$

\section{Dissolution results}

Table (4): Cumulative \% Dissolution Data of Rasagiline from Azilect® $1 \mathrm{mg}$ Tablets (Teva Pharmaceuticals, USA), the Reference product after (minutes).

\begin{tabular}{|c|c|c|c|c|}
\hline \multirow{2}{*}{ EXP No. } & \multicolumn{5}{|c|}{ Cumulative \% Dissolution of Data of Rasagiline from Azilect ${ }^{\circledR}$ I mg Tablets (Teva } \\
& $\mathbf{1 0}$ & $\mathbf{1 5}$ & $\mathbf{3 0}$ & $\mathbf{4 5}$ \\
\hline I & 91.36 & 91.29 & 86.91 & 87.82 \\
\hline II & 95.46 & 92.04 & 91.99 & 87.40 \\
\hline III & 91.88 & 89.42 & 95.70 & 87.10 \\
\hline IV & 90.99 & 90.59 & 92.19 & 90.94 \\
\hline V & 88.54 & 88.06 & 91.19 & 89.70 \\
\hline VI & 92.65 & 89.77 & 94.78 & 89.71 \\
\hline VII & 90.46 & 88.45 & 97.79 & 89.52 \\
\hline VIII & 90.65 & 89.28 & 94.57 & 89.09 \\
\hline IX & 88.41 & 88.18 & 92.23 & 88.73 \\
\hline X & 93.90 & 88.45 & 97.04 & 89.08 \\
\hline XI & 91.96 & 87.11 & 98.14 & 91.93 \\
\hline XII & 93.01 & 89.77 & 92.59 & $\mathbf{8 9 . 2 1}$ \\
\hline Average & $\mathbf{9 1 . 6 1}$ & $\mathbf{8 9 . 3 7}$ & $\mathbf{9 3 . 7 6}$ & \\
\hline
\end{tabular}

\section{Similarity and Difference Factors}

The calculated Difference factor between the dissolution profile of Rasagiline from Parkintreat $1 \mathrm{mg}$ Tablets (SEDICO For Inspire Pharmaceutical Co. (IPC Pharma), Egypt) and Azilect ${ }^{\circledR} 1 \mathrm{mg}$ Tablets (Teva Pharmaceuticals, USA) $=7$

$$
f_{1}=\left\{\left[\sum_{t=1}^{n} 1 R_{t}-T_{t}\right],\left[\sum_{t=1}^{n} R_{t}\right]\right\} .100
$$

According to the FDA Guidance for Industry, for dissolution profiles to be considered similar, the difference factor should be close to 0 . Generally, the difference factor values up to $15(0-15)$ ensure sameness or equivalence of the two profile curves and, thus, of the performance of the test and reference products.
The calculated Similarity factor between the dissolution profile of Rasagiline from Parkintreat $1 \mathrm{mg}$ Tablets (SEDICO For Inspire Pharmaceutical Co. (IPC Pharma), Egypt) and Azilect ${ }^{\circledR} \quad 1 \quad \mathrm{mg}$ Tablets (Teva Pharmaceuticals, USA) $=60$

$$
f_{2}=50 \cdot \log \left\{\left[1+(1 / n) \sum_{t=1}^{n}\left(R_{t}-T_{t}\right)^{2}\right]^{-0.5} \cdot 100\right\}
$$

According to the FDA Guidance for Industry, for dissolution profiles to be considered similar, the similarity factor should be greater than 50 (50-100) ensure sameness or equivalence of the two profile curves and, thus, of the performance of the test and reference products ${ }^{[17]}$. 
Table (5): Cumulative \% Dissolution Data of Rasagiline from Parkintreat $1 \mathrm{mg}$ Tablets (SEDICO For Inspire Pharmaceutical Co. (IPC Pharma), Egypt), the Test product after (minutes).

\begin{tabular}{|c|c|c|c|c|}
\hline \multirow{2}{*}{ EXP No. } & \multicolumn{4}{|c|}{$\begin{array}{c}\text { Cumulative \% Dissolution of Data of Rasagiline from Parkintreat 1 mg Tablets (SEDICO For } \\
\text { Inspire Pharmaceutical Co. (IPC Pharma), Egypt), after (minutes) }\end{array}$} \\
\cline { 2 - 5 } & $\mathbf{1 0}$ & $\mathbf{1 5}$ & $\mathbf{3 0}$ & $\mathbf{4 5}$ \\
\hline I & 87.61 & 99.22 & 94.10 & 95.85 \\
\hline II & 88.25 & 97.47 & 95.45 & 94.65 \\
\hline III & 91.37 & 96.00 & 98.63 & 94.87 \\
\hline IV & 81.61 & 95.75 & 101.73 & 97.12 \\
\hline V & 84.59 & 94.42 & 99.21 & 96.80 \\
\hline VI & 85.86 & 93.33 & 100.25 & 97.79 \\
\hline VII & 89.35 & 95.03 & 101.11 & 96.38 \\
\hline VIII & 80.52 & 94.33 & 103.91 & 95.44 \\
\hline IX & 83.82 & 93.08 & 101.13 & 95.20 \\
\hline X & 86.32 & 93.50 & 102.10 & 96.10 \\
\hline XI & 90.03 & 93.09 & 102.98 & 94.36 \\
\hline XII & 81.63 & 93.84 & 103.37 & $\mathbf{9 5 . 9 3}$ \\
\hline Average & $\mathbf{8 5 . 9 1}$ & $\mathbf{9 4 . 9 2}$ & $\mathbf{1 0 0 . 3 3}$ & \\
\hline
\end{tabular}

Limits: Not less than $80 \%$ dissolved after 45 minutes.

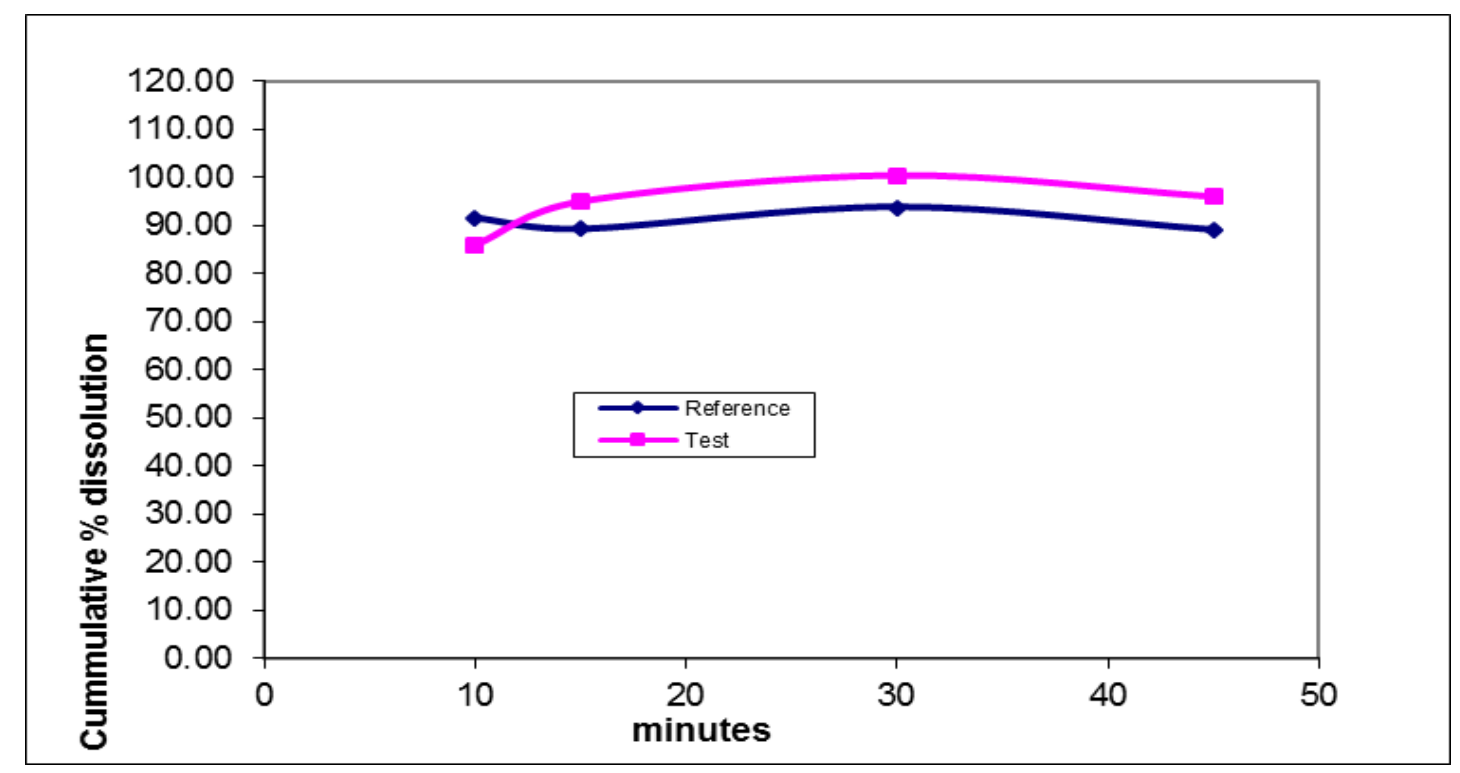

Fig. 5: Dissolution Profile of Rasagiline from Parkintreat $1 \mathrm{mg}$ Tablets (SEDICO for Inspire Pharmaceutical Co. (IPC Pharma), Egypt), the test product and Azilect ${ }^{\circ} 1 \mathrm{mg}$ Tablets (Teva Pharmaceuticals, USA), the reference product.

\section{Conclusion}

A new method using fluorescence detection method has been developed for estimation of Rasagiline Mesylate in the tablet dosage form. The proposed method is simple, accurate, sensitive, and linear across the specified range. So that, it is suitable for the determination of Rasagiline Mesylate in tablet dosage form.

\section{References}

1) Muangpaisan, W., Mathews, A., Hori, H. and Seidel, D. (2011). A systematic review of the worldwide prevalence and incidence of Parkinson's disease. Journal of the Medical Association of Thailand = Chotmaihet thangphaet. 94(6):749-755.
2) Finberg, J. P. (2010). Pharmacology of Rasagiline, a New MAO-B Inhibitor Drug for the Treatment of Parkinson's Disease with Neuroprotective Potential. Rambam Maimonides Med J. 1(1):e0003.

3) Weinreb, O., Amit, T., Bar-Am, O. and Youdim, M. B. H. (2010). Rasagiline: A novel antiParkinsonian monoamine oxidase-B inhibitor with neuroprotective activity. Progress in Neurobiology. 92(3):330-344.

4) Thebault, J. J., Guillaume, M. and Levy, R. (2004). Tolerability, safety, pharmacodynamics, and pharmacokinetics of rasagiline: a potent, selective, and irreversible monoamine oxidase type B inhibitor. Pharmacotherapy. 24(10):1295-1305. 
5) Heimann, M. R. (2006). Chemistry Reviews. Center for drug evaluation and research. 2006:38.

6) Youdim, M. B., Gross, A. and Finberg, J. P. (2001). Rasagiline [N-propargyl-1R(+)aminoindan], a selective and potent inhibitor of mitochondrial monoamine oxidase B. British journal of pharmacology. 132(2):500-506.

7) Tekkeli, S. E. K., Onal, A. and Bahadori, F. (2013). Development and Validation of Spectrophotometric Methods for the Determination of Rasagiline in Pharmaceutical Preparations. J Spectrosc. 2013.

8) Sevim, S. and Erk, N. (2015). Applications of high performance liquid chromatographic and spectrophotometric techniques for determination of rasagiline mesylate in dosage forms. J Anal Chem. 70(5):600-607.

9) Fernández, M., Barcia, E. and Negro, S. (2009). Development and validation of a reverse phase liquid chromatography method for the quantification of rasagiline mesylate in biodegradable PLGA microspheres. Journal of Pharmaceutical and Biomedical Analysis. 49(5):1185-1191.

10) Reddy, P. S., Sudhakar Babu, K. and Kumar, N. (2013). Development and validation of a stabilityindicating RP-HPLC method for the simultaneous estimation of process related impurities and degradation products of rasagiline mesylate in pharmaceutical formulation. Journal of chromatographic science. 51(3):242-249.

11) Ravi, P. R., Aditya, N., Cherian, L. and Patil, S. (2013). LC method for determination of rasagiline mesylate in different plasma matrices and its application to oral pharmacokinetic study in rabbits. Journal of chromatographic science. 51(1):1-7.

12) Kathirvel, S., Satyanarayana, S. V. and Devalarao, G. (2012). Development and Validation of a Stability-Indicating HPTLC Method for Analysis of Rasagiline Mesylate in the Bulk Drug and Tablet Dosage Form. Chromatography Research International. 2012:6.

13) Ma, J., Chen, X., Duan, X., Deng, P., Wang, H. and Zhong, D. (2008). Validated LC-MS/MS method for quantitative determination of rasagiline in human plasma and its application to a pharmacokinetic study. Journal of Chromatography B. 873(2):203-208.

14) Song, M., Wang, L., Zhao, H., Hang, T., Wen, A., Yang, L. and Jia, L. (2008). Rapid and sensitive liquid chromatography-tandem mass spectrometry: Assay development, validation and application to a human pharmacokinetic study. Journal of Chromatography B. 875(2):515-521.

15) Guideline IHT. (2005). Validation of analytical procedures: text and methodology. Q2 (R1). 2005;1.

16) FDA U. Dissolution Methods 2010 [cited 1/5/2013]. Available from: https://www.accessdata. fda.gov/scripts/cder/dissolution/dsp_SearchResults.c fm.

17) Food U, Administration D. Guidance for industry (1997). Dissolution testing of immediate release solid oral dosage forms. Center for Drug Evaluation and Research, Rockville. 